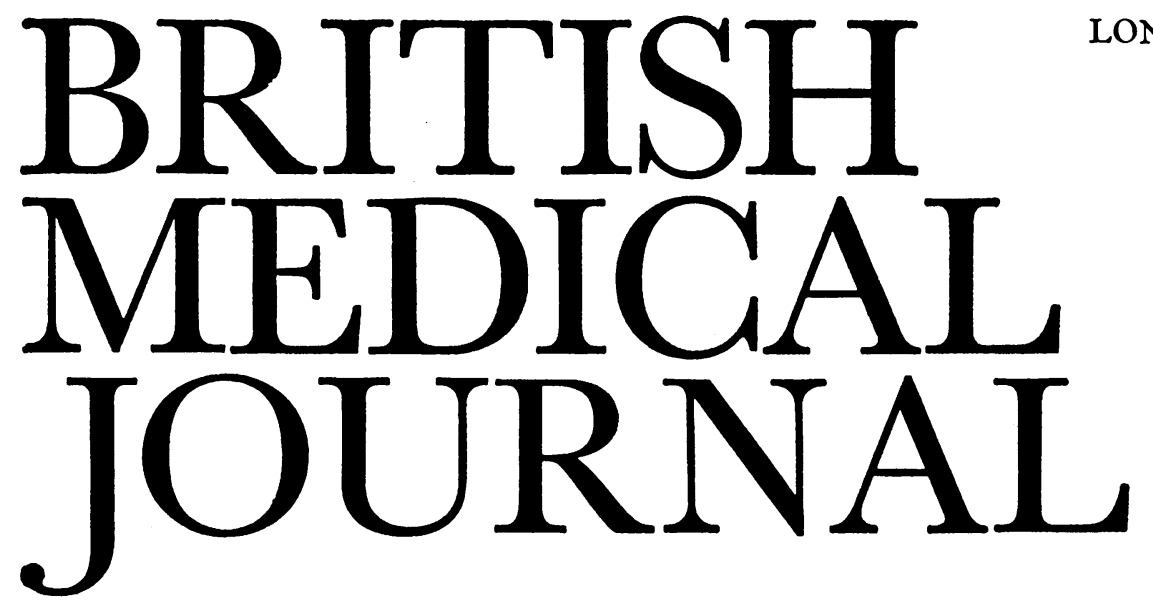

\title{
The Becker type X-linked muscular dystrophy
}

The most severe form of muscular dystrophy is the Duchenne type, which in Britain affects about 30 per 100000 males surviving to the age of 5 years. This form of the disease begins in infancy or early childhood with difficulty in walking, in rising from the floor, and in climbing stairs. It is steadily progressive and generally leads to confinement to a wheelchair by about the age of 10 ; relatively few patients survive much beyond the age of 20 , most dying from respiratory infection or cardiac failure. ${ }^{1}$ This disease is inherited as an X-linked recessive trait, affecting males and being transmitted by female carriers who are generally unaffected clinically, though some show minimal evidence of muscular weakness and many have a rise in serum creatine kinase activity. Recent research has defined methods of identifying these female carriers who are liable to pass the disease on to their sons. ${ }^{1}$

Becker $^{2-4}$ was the first to draw attention to the existence of a more benign form of X-linked muscular dystrophy, and Emery and Skinner ${ }^{-5}$ have now analysed the findings in 29 men with the disease from 10 families in which a total of 67 individuals were known to have been affected. As they point out, sporadic cases may be difficult to identify. Firstly, young patients with an unusually early onset of the Becker variety may cause difficulty in distinction from the Duchenne type; secondly, in patients in whom the disease arises later the condition may closely resemble the limb-girdle muscular dystrophy syndrome, which is usually inherited as an autosomal recessive trait. Generally, however, the disease begins later in the Becker type than in the Duchenne, with weakness first developing late in the first decade or early in the second and occasionally even in early adult life. The clinical pattern of muscular weakness is similar to that $\mathrm{s}$ e $\mathrm{l}$ in Duchenne muscular dystrophy. The hip flexors, quadriceps, and anterior tibial muscles tend to be affected early in the legs, often with appreciable enlargement of the calf muscles, while in the arms the serrati, pectorals, biceps, and brachioradiales are generally the first muscles to become weak. In the cases reported by Emery and Skinner ${ }^{5}$ the mean age of onset was $11 \cdot 1$ years with a range of 2.5 to 21 years. Progression is, however, much slower than in the Duchenne variety, so that affected individuals do not usually become confined to wheelchairs until the disease has been clinically manifest for 20 or 30 years, and the average life expectancy of these patients is nowadays only slightly decreased. The condition is distinctly less common than the
Duchenne variety, though no reliable figures for prevalence have yet been reported.

In the Becker variety, as in the Duchenne, the serum creatine kinase activity is substantially raised, especially in the early stages of the disease, and its estimation can be used for the detection of preclinical cases in boys born in families known to be at risk. Nevertheless, estimation of this enzyme in the serum is less helpful in identifying female carriers than in the Duchenne type. ${ }^{6}$ In some families evidence has been found ${ }^{7}$ suggesting possible linkage between the Becker gene and those of colour blindness and the $\mathrm{Xg}$ blood group, but there is no evidence of similar linkage with the gene responsible for the Duchenne type. Another point of distinction is that the cardiomyopathy which is constantly present in Duchenne muscular dystrophy gives a characteristic abnormality best expressed by the algebraic sum of the dimensions of the $R$ and $S$ waves in lead Vl of the electrocardiogram; such abnormalities are not observed in the Becker type, in which cardiac lesions occur late, if at all. ${ }^{5}$

It is perhaps unfortunate that Er ery an 1 Skinner $^{5}$ did not describe in detail the histological finc. gs ,bserved on muscle biopsy in their c ses, though a biopsy was done in at least one affected male in each family, nor did they describe the results of electromyographic studies. Such investigations are now obligatory in the diagnosis of muscular dystrophy, including the Becker type, because of recent evidence that benign spinal muscular atrophy of the Kugelberg-Welander variety may give clinical ma) ifesta:ions closely resembling those of Becker muscular dystrophy. This condition accounts for many patients previously diagnosed as suffering from the limb-girdle muscular dystrophy syndrome. ${ }^{18}$ In such cases secondary myopathic change in muscle, superimposed upon the effects of the primary denervating process, may cause a rise in serum creatine kinase activity and changes in muscle biopsies which may be misconstrued by the unwary as being indicative of a primary myopathy. ${ }^{9}$ As spinal muscular atrophy is usually due to an autosomal recessive trait the distinction is important for genetic counselling. Nevertheless, the ctudies reported by Emery and Skinner ${ }^{5}$ have done a useful : $r$ 'ce in characterising the wide variations in age of presentatic $n$ and clinical course which may be seen in the benign Becker variety of muscular dystrophy and in highlighting important points of distinction between it and the Duchenne. The single most useful diagnostic feature 
was the age at which the patient became confined to a wheelchair. Plainly, however, the other criteria mentioned, though less exact, must be used in attempting to define the prognosis in an early case and in formulating appropriate genetic advice.

1 Walton, J N, and Gardner-Medwin, D, Disorders of Voluntary Muscle, 3rd edn. Edinburgh, Churchill Livingstone, 1974.

2 Becker, P E, and Kiener, F, Archiv für Psychiatrie und Nervenkrankheiten, 1955, 193, 427.

${ }^{3}$ Becker, P E, Acta Genetica et Statistica Medica, 1957, 7, 303.

4 Becker, P E, Revue Canadienne de Biologie, 1962, 21, 551.

5 Emery, A E H, and Skinner, R, Clinical Genetics, 1976, 10, 189.

${ }^{6}$ Emery, A E H, et al, British Medical fournal, 1967, 4, 422.

' Emery, A E H, Smith, C A B, and Sanger, R, Annals of Human Genetics, $1969,32,261$.

8 Tomlinson, B E, Walton, J N, and Irving, D, fournal of the Neurological Sciences, 1974, 22, 305.

${ }^{9}$ Mastaglia, F L, and Walton, J N, Fournal of the Neurological Sciences, $1971,12,15$.

\section{Intrapartum fetal monitoring for all?}

Should all women have intrapartum fetal monitoring? Is the case proved? These questions have wide implications both clinically and economically, and answers are needed as soon as possible. By unselected fetal monitoring is meant observation of all patients in labour with well-established techniques using the cardiotokagraph and, if necessary, fetal blood sampling. The more recent development of computerised monitoring for fetal heart rate and uterine pressure ${ }^{1}$ is still at the research stage, and its practical value cannot yet be evaluated.

Several obstetric units have reported series in which routine intrapartum fetal monitoring has been claimed to lead to improved perinatal mortality. ${ }^{2}{ }^{3}$ None so far has given sufficient data to prove the case beyond all question. With so many changes in obstetric practice in recent years it has been difficult to apportion the relative importance of each in reducing perinatal mortality. For example, elective induction of labour has resulted in fewer deaths from asphyxia (the "mature, cause unknown" deaths of Baird, Walker, and Thomson). ${ }^{4}$ With a high rate of induction of labour at term the incidence of unexpected intrapartum death is very low indeed. Increasing use of contraception of all kinds has reduced parity, introducing another factor which will help to reduce perinatal mortality in the present generation of mothers. If indeed unselected fetal monitoring could reduce perinatal mortality further the effect would become apparent only in a very large series of cases.

Experience with high-risk patients has shown that when continuous fetal heart rate monitoring is combined with the measurement of uterine action and the use of fetal blood $\mathrm{pH}$ measurements when required this provides a reliable system for the early detection of intrapartum fetal asphyxia. ${ }^{5}$ There is no doubt that this type of monitoring is indicated in all risk cases -and risk should be interpreted widely for this purpose. But the crucial question is whether fetal monitoring can improve fetal mortality in women with none of the accepted risk factors. If the answer to this question is unequivocally positive, then monitoring will be mandatory for all women in labour.

Estimates suggest that one monitor is required for $300-400$ deliveries, so that a maternity unit delivering 2000 patients a year would require five cardiotokagraphs if all labour were to be monitored. In addition, fetal blood sampling equipment would be needed, together with the necessary $\mathrm{pH}$ measurement apparatus and trained staff to use and maintain it. Provision of staff and equipment on the scale required to provide nation- wide monitoring services would be very expensive-and at a time when the DHSS is suggesting cuts in spending on obstetrics. ${ }^{6}$ Clearly, therefore, this is an example of a decision which should be taken on the basis of a strictly controlled randomised trial, in which the outcome of labour is compared in low risk patients with and without continuous intrapartum monitoring. Some might question the ethics of such a trial, but there is enough genuine doubt-and the issues are sufficiently important-to justify it. Furthermore, a large number of patients will be needed, for with low risk patients the perinatal mortality should be low in any case. Possibly 5000 patients might be needed to establish a clear result, but that number is not beyond the capabilities of a single large centre with the proper facilities.

Meanwhile there is a wide spectrum of risk cases for whom continuous intrapartum fetal monitoring will reduce the chances of intrapartum stillbirth and for that reason every obstetric unit should be able to offer the facility to those patients who need it.

${ }^{1}$ Crawford, J W, American fournal of Obstetrics and Gynecology, 1975, 121, 342

${ }^{2}$ Edington, P T, Sibanda, J, and Beard, R W, British Medical fournal, $1975,2,341$.

${ }^{3}$ Lee, W K, and Baggish, M S, Obstetrics and Gynecology, 1976, 47, 516.

4 Baird, D, Walker, J, and Thomson, A M, Fournal of Obstetrics and Gynaecology of the British Empire, 1954, 61, 433.

${ }^{5}$ Beard, R W, et al, fournal of Obstetrics and Gynaecology of the British Commonwealth, 1971, 78, 765.

${ }^{6}$ DHSS, Priorities in Health and Social Services. London, HMSO, 1976.

\section{Chemotherapy for varicella-zoster infections}

Varicella is always unpleasant and sometimes life-threatening. This is true whether it occurs in its classical form as chickenpox or its variant, herpes zoster. In common with infections by other herpesviruses such as herpes simplex and by cytomegalovirus, herpes zoster seems to be occurring more frequently, and sometimes in a particularly virulent guise, partly at least because of the increasing use of immunosuppressive treatment.

Nevertheless, in parallel with the march of the herpesviruses has come a generation of chemotherapeutic agents effective against them, continually modified chemically and improved pharmaceutically. ${ }^{1}$ Idoxuridine is certainly of value when applied in a strength of $40 \%$ in dimethylsulphoxide (DMSO) to skin lesions. The place of cytosine arabinoside (ara-C) is doubtful, and it has in fact been reported to potentiate herpes simplex infections in mice ${ }^{2}$ and herpes zoster in man. ${ }^{3}$ Indeed, it has been used to improve the yield of virus in some experimental systems in which the cells have been pretreated with it. On the other hand, Lefkowitz et $a l^{2}$ found vidarabineadenosine arabinoside (ara-A)-effective against herpes simplex infections in mice; even, surprisingly, as late as three days after infection. In contrast ara-C appeared to potentiate the infection and idoxuridine failed to protect the mice.

There is no vaccine available against the chickenpox virus, and, according to Juel-Jensen, ${ }^{4}$ less than half of the clinical students at the Oxford Medical School have antibodies against it. He has recently reported the treatment of two of these students suffering from varicella with adenosine arabinoside. One had a temperature of $40^{\circ} \mathrm{C}$, a tender liver, and evidence of hepatocellular lesions. The other had severe atopic eczema. His temperature was $39.9^{\circ} \mathrm{C}$, and he was delirious. Both were 